\title{
ANÁLISE DA PRODUÇÃO CIENTÍFICA SOBRE ESQUIZOFRENIA
}

\author{
ANALYSIS OF SCIENTIFIC PRODUCTION ON SCHIZOPHRENIA
}

\section{Juliana Lidiane Rêgo da Silva ${ }^{a^{*}}$, Livia Maria de Melo Santos ${ }^{b^{*}}$, Uirassú Tumpinambá Silva de Lima ${ }^{c^{*}}$, Tâmyssa Simões dos Santos ${ }^{\mathrm{d}^{* *}}$, Karen da Silva Santos ${ }^{\mathrm{e}^{* * *}}$, Pétalla Morganna Figueiredo Pessoa de Barros ${ }^{* * * *}$}

\author{
ajulianalidiane@hotmail.com, bliviaa.melo@hotmail.com, cuirassulima@yahoo.com.br, dtamyssa-simoes@hotmail.com, \\ ekaren-web@hotmail.com, fpetalla_morganna@hotmail.com \\ *Centro Universitário Cesmac - Maceió (AL), Brasil \\ **Centro Universitário Mauricio de Nassau - Maceió (AL), Brasil \\ ***Universidade de São Paulo - Ribeirão Preto (SP), Brasil \\ ****Universidade Federal de Alagoas - Maceió (AL), Brasil
}

Data de recebimento: 16/03/2016

Data de aceite: 29/05/2016

\section{RESUMO}

Introduçáo: A esquizofrenia é uma doença psiquiátrica crônico-degenerativa que ocupa a primeira posição na lista das doenças mentais, sendo considerada o transtorno mental mais grave e de significativa repercussão para a saúde pública. É vista como um fenômeno deteriorante, que causa prejuízos na vida da pessoa acometida e de seus familiares. Objetivo: Analisar a produção científica sobre esquizofrenia, no período de 1983 a 2015, publicada na REBEn. Método: Trata-se de uma revisão integrativa da literatura. A busca bibliográfica foi realizada no periódico da REBEn indexada nas seguintes bases de dados: Lilacs, Index Nursing, CINAHL e Scielo. Foram incluídos na pesquisa artigos originais, com texto na íntegra, disponíveis em suporte eletrônico. Os descritores utilizados foram: esquizofrenia, sofrimento psíquico e enfermagem. Foram selecionados e analisados sete artigos científicos. Resultados: Em 2005 e 2012 ocorreu o maior número de publicaçóes. Quanto à titulação dos autores dos artigos, a maioria teve a participaçáo de mestres e doutores. Em relação ao estado federativo, a maioria dessa produção concentrouse na regiấo Sudeste, com abordagem qualitativa de forma unânime. O cenário das pesquisas teve destaque para as instituições hospitalares. Conclusão: Há poucos estudos publicados na área de enfermagem sobre a esquizofrenia, fato evidenciado pela diminutiva produçâo que aborda a questão ao longo de 32 anos de publicação da REBEn. As produçôes científicas encontradas mostraram-se importantes para mudanças de conduta das práticas de enfermagem, no entanto, nota-se a necessidade de estudos com essa temática.

Palavras-chave: Esquizofrenia; sofrimento psíquico; enfermagem.

\section{ABSTRACT}

Introduction: Schizophrenia, object of this review, is a chronic degenerative mental disease. It occupies the top position of the mental illness list, being considered the most serious mental disorder, with significant repercussions on public health. Schizophrenia is known as a deteriorating phenomenon, which causes damages on the life of the affected person and his family. Goals: To analyze the scientific literature about schizophrenia, in the period between 1983 and 2015, published at REBEn. Methods: This is an integrative literature review. The literature research was made in the journal REBEn, which can be found on the following databases: Lilacs, Nursing Index, CINAHL and Scielo. The research included original articles with full text available in electronic support. The descriptors used were: schizophrenia, mental suffering and nursing. Seven scientific articles were selected and analyzed. Results: In 2005 and 2012, the higher number of publications could be found. Regarding the authorship of the articles, most had the participation of masters and doctors. Most of the researched production was concentrated in the Southeast Region, with unanimous qualitative approach. Hospitals were the biggest scenario of this research. Conclusion: There are few studies published in Nursing about schizophrenia, as evidenced by the decreasing of production about it for 32 years of publication of REBEn. The scientific productions proved to be important to change behaviors on nursing practice, however, there is a need for more studies on this subject.

Keywords: Schizophrenia; psychological distress; nursing. 


\section{Introdução}

A esquizofrenia é uma doença psiquiátrica crônico-degenerativa que ocupa a primeira posição na lista das doenças mentais, sendo considerada o transtorno mental mais grave. Enquadra-se como um dos principais problemas de saúde pública do Brasil, o que exige onerosos investimentos e custos ao Sistema Único de Saúde (SUS). É caracterizada pela longa duraçáo e períodos de crise e flutuação dos sinais e sintomas, e geralmente seus pacientes apresentam vários surtos no primeiro anos da doença ${ }^{1}$.

É vista como uma doença deteriorante, que leva a prejuízos na vida da pessoa acometida e de familiares. O estigma da doença e sobrecarga gerada nos familiares fortalece a ideia de que pessoas acometidas pela esquizofrenia necessitam de isolamento social, através de hospitais psiquiátricos ou casas de longa permanência. Todavia, nos dias atuais pode-se observar com a atual reforma psiquiátrica brasileira a reinserção desses portadores ao seio familiar ${ }^{2}$.

De acordo com a Organização Mundial de Saúde (OMS), $1 \%$ da populaçáo mundial sofre de esquizofrenia. No Brasil surgem cerca de 75 mil novos casos por ano, representando 50 casos para cada 100 mil habitantes. Cerca de 2 milhóes de brasileiros são acometidos pela doença, sem contar que há uma mistificação (tabus, preconceito) sobre a doença, gerado pelo baixo conhecimento da populaçáo. Pelo seu poder incapacitante, afeta todos os setores da vida do portador, desde atividades da vida diária até mesmo assuntos profissionais, e o mais agravante é que a reintegração na sociedade e na família torna-se muito difícil ${ }^{1,3,4}$.

Apesar do devastador efeito social que a esquizofrenia traz, ainda hoje não se sabe sua causa real. Alguns estudiosos afirmam que trauma na infância, perda de um ente querido, estresse, psicose, disfunção social e familiar podem contribuir para desencadear a doença, que geralmente se manifesta no final da adolescência ou início da fase adulta, e atinge em igual proporção homens e mulheres. A pessoa com esquizofrenia tem dificuldade para reconhecer a realidade, tendo como principais manifestaçóes clínicas: delírio, alucinações, alteraçóes do pensamento, alteraçóes da efetividade, entre outros sintomas que podem surgir com a evolução da doença ${ }^{1,5,6}$.

Bleuler introduziu os subtipos: paranoide, hebefrênico e catatônico. Nos anos de 1980, o pesquisador Crow dividiu a doença em dois subtipos: I (ou positivo), havendo predomínio de alucinaçôes e delírios; e II (ou negativo), representando pelo embotamento afetivo e pobreza de discurso. Os aspectos que se destacam na esquizofrenia são: alucinações e delírios, transtornos de pensamento e fala, perturbação das emoções e do afeto, déficits cognitivos?
$\mathrm{Na}$ visão da família, ter um pessoa com esquizofrenia significa sobrecarga e desgaste físico e emocional. $\mathrm{Na}$ perspectiva dos familiares, essa sobrecarga pode ser dividida em objetivas e subjetivas, sendo a sobrecarga objetiva caraterizada pelas atividades diárias que os cuidadores precisam realizar para atender às necessidades da pessoa com transtorno mental. Cabe destacar que os desejos do doente, na sua maioria, não correspondem às expectativas da família, gerando assim conflitos internos, causados pelas mudanças na rotina social. Em relação ao aspecto subjetivo, pode ser visualizado através da reação emocional do cuidador, suas perspectivas em relação ao doente, sua necessidade de conhecer a patologia e seu sentimento em estar sofrendo a sobrecarga, o que pode desestabilizar sua saúde mental ${ }^{8}$.

A pessoa com esquizofrenia apresenta dificuldades para o autocuidado, acarretando consequentemente na sobrecarga familiar, que convive com o sentimento de aflição, depressão, isolamento, tristeza, culpa e angústia, afetando diretamente a qualidade de vida do familiar cuidador, que coloca suas vontades e desejos em segundo plano ${ }^{1}$.

A qualidade de vida dos cuidadores de portadores de transtornos mentais é prejudicada, havendo diversas consequências, como falta de apoio social, isolamento, estresse, cansaço, frustração, ansiedade, baixa autoestima, falta de esperança, prejuízo nas atividades de lazer e preocupaçóes sobre o futuro. Essas consequências também podem ser expressas em termos de sobrecargas financeiras, na rotina familiar e em forma de manifestação de doença física ou emocional ${ }^{2}$.

Os profissionais da saúde devem auxiliar os familiares/cuidadores das pessoas com esquizofrenia, ajudando-os no desenvolvimento de um plano terapêutico que inclua: horários das medicações, forma de abordagem, contatos de serviços de saúde, agendamento de consultas e exames e programaçóes de momento de lazer com o paciente e a família para melhorar o vínculo familiar. Percebe-se, assim, que o profissional no momento da consulta deve coletar dados do histórico familiar, sendo este imprescindível para nortear as decisóes e orientações passadas para famíliaa ${ }^{2,9,10}$.

O plano terapêutico baseia-se na inserção/reinserçáo das pessoas com esquizofrenia no convívio familiar, considerando a família como o espaço fundamental para o cuidado. No entanto, necessita de eficiente reorganização dos serviços de saúde e preparo dos profissionais. Considerando essas transformações, torna-se fundamental ampliar o cuidado para a família ${ }^{2}$.

$\mathrm{O}$ cuidador principal, que tem o contato imediato com o paciente, sofre as sobrecargas de doenças físicas e emocionais, consequentes dos desgastes gerados pelo 
comportamento dos seus doentes e pela difícil tarefa de vigiá-los. Essa situação acarreta em uma experiência angustiante, vindo os sentimentos de incerteza, pensamentos negativos em relação ao futuro, que envolvem não só as perspectivas do paciente, mas também ao próprio futuro do cuidador ${ }^{9,11}$.

Tais evidências trazem a questão norteadora: o que a Revista Brasileira de Enfermagem (REBEn) tem descrito sobre a esquizofrenia?

A escolha desse periódico se deu pelo fato de ser a revista mais tradicionais, que publica os trabalhos das mais representativas instituições de enfermagem do país, indexada no sistema Scielo, e por estar ligada à Associação Brasileira de Enfermagem (ABEn).

Diante das informaçôes aqui tecidas, considera-se importante pesquisar estudos que abordem o tema esquizofrenia e sua relação com os familiares, bem como os cuidados de enfermagem, justific ando assim o interesse em desenvolver esta revisão, que teve como objetivo analisar a produção científica sobre esquizofrenia na $R E B E n$. Acredita-se que o desenvolvimento deste estudo trará subsídios que possam ajudar os familiares e pessoas com esquizofrenia.

\section{Metodologia}

Trata-se de uma pesquisa bibliográfica que se utilizou do delineamento da revisão integrativa da literatura como método. O levantamento foi realizado nas seguintes bases de dados: Lilacs, Index Nursing, CINAHL e Scielo, que indexam a REBEn, utilizando-se dos seguintes descritores: esquizofrenia, sofrimento psíquico e enfermagem.

O presente estudo foi organizado e sistematizado de acordo com as etapas a seguir: escolha do tema, levantamento bibliográfico, eleição dos objetivos específicos, formulação do problema, seleção das fontes, leitura dos artigos, fichamento, análise, interpretação e redação do texto $^{12,13}$.

A REBEn é o periódico mais antigo dentre todas as revistas que publicam na área da enfermagem. Foi criada em 1932, sendo pioneira quando se trata de representar a enfermagem brasileira. Executa um importante papel de divulgação da $\mathrm{ABEn}$, exerce a função de expandir pelos meios impressos e eletrônicos as diversas produções científicas, cujo saber perpassa a área da enfermagem, sendo de grande valia quando se pretende abordar outra temática que tenha como foco a enfermagem ${ }^{14}$.

Foram encontrados sete artigos, no período de 1983 a 2015, nas bases de dados pesquisados. Em seguida foi realizada uma leitura minuciosa para averiguar os artigos que continham informaçóes pertinentes aos objetivos do estudo. As variáveis investigadas foram: quantidade de autores, ano de publicação, descritores utilizados, estado federativo, titulação dos autores, cuidados indicados, metodologia utilizada, cenários das pesquisas, sujeitos investigados e temática utilizada. Todos os artigos encontrados atendiam aos objetivos propostos, e em virtude disso não houve exclusão.

\section{Resultados e discussão}

Devido à importância científica que representa a REBEn na área de enfermagem, este estudo buscou explorar os artigos com a temática esquizofrenia. As variáveis (quantidade de autores, ano de publicação, descritores utilizados, estado federativo, titulação dos autores, cuidados indicados, metodologia utilizada, cenário da pesquisa, sujeitos investigados e temática utilizada) serão apresentadas e discutidas nesta ordem. Os resultados da síntese dos artigos selecionados para análise foram apresentados no Quadro 1.

Quadro 1: Apresentação dos artigos publicados na REBEn com o tema esquizofrenia, 2015.

\begin{tabular}{|c|c|c|c|c|c|}
\hline Ano de publicaçáo & Descritores & Titulaçóes & Metodologia & $\begin{array}{l}\text { Cenário da } \\
\text { pesquisa }\end{array}$ & $\begin{array}{c}\text { Sujeitos } \\
\text { investigados }\end{array}$ \\
\hline 2001 & $\begin{array}{l}\text { Esquizofrenia, per- } \\
\text { cepção e sociedade }\end{array}$ & $\begin{array}{l}\text { Graduada e } \\
\text { doutor }\end{array}$ & $\begin{array}{l}\text { Pesquisa de campo } \\
\text { - fenomenológico }\end{array}$ & $\begin{array}{l}\text { Instituiçãoo } \\
\text { hospitalar }\end{array}$ & $\begin{array}{c}\text { Pessoa com } \\
\text { Esquizofrenia }\end{array}$ \\
\hline 2005 & $\begin{array}{l}\text { Esquizofrenia; clo- } \\
\text { zapina; psicoterapia } \\
\text { de grupo; enferma- } \\
\text { gem psiquiátrica. }\end{array}$ & $\begin{array}{l}\text { Especialista, } \\
\text { mestre e } \\
\text { doutor }\end{array}$ & $\begin{array}{l}\text { Pesquisa de avaliação - } \\
\text { tipo descritivo explora- } \\
\text { tório, com acompanha- } \\
\text { mento de grupo. }\end{array}$ & $\begin{array}{l}\text { Instituiçáa hos- } \\
\text { pitalar-Hospital } \\
\text { das Clínicas } \\
\text { (USP) }\end{array}$ & $\begin{array}{l}\text { Pessoa com esquizo- } \\
\text { frenia e familiares }\end{array}$ \\
\hline 2005 & $\begin{array}{l}\text { Qualidade de } \\
\text { vida; cuidadores; } \\
\text { esquizofrenia. }\end{array}$ & Doutor & $\begin{array}{l}\text { Pesquisa exploratório- } \\
\text {-descritiva transversal de } \\
\text { campo com uma análise } \\
\text { quanti-qualitativa }\end{array}$ & $\begin{array}{c}\text { Unidade } \\
\text { ambulatorial }\end{array}$ & $\begin{array}{l}\text { Familiares cuidado- } \\
\text { res de pessoas com } \\
\text { esquizofrenia }\end{array}$ \\
\hline
\end{tabular}

continua... 
Quadro 1: Continuação.

\begin{tabular}{|c|c|c|c|c|c|}
\hline Ano de publicaçáo & Descritores & Titulaçóes & Metodologia & $\begin{array}{c}\text { Cenário da } \\
\text { pesquisa }\end{array}$ & $\begin{array}{c}\text { Sujeitos } \\
\text { investigados }\end{array}$ \\
\hline 2011 & $\begin{array}{l}\text { Enfermagem; cuida- } \\
\text { do de enfermagem; } \\
\text { família, relações } \\
\text { interpessoais. }\end{array}$ & $\begin{array}{l}\text { Graduadas e } \\
\text { mestre }\end{array}$ & $\begin{array}{l}\text { Pesquisa qualitati- } \\
\text { va numa abordagem } \\
\text { fenomenológica }\end{array}$ & Domicílio & Familiares \\
\hline 2012 & $\begin{array}{l}\text { Processo saúde- } \\
\text {-doença; esquizo- } \\
\text { frenia; psicanálise; } \\
\text { enfermagem. }\end{array}$ & $\begin{array}{l}\text { Duas autoras } \\
\text { são graduan- } \\
\text { das; não há } \\
\text { informação } \\
\text { quanto à } \\
\text { titulação das } \\
\text { outras duas. }\end{array}$ & Estudo qualitativo & $\begin{array}{c}\text { Centro } \\
\text { de Atenção } \\
\text { Psicossocial, } \\
\text { modalidade III. }\end{array}$ & $\begin{array}{c}\text { Pessoa com } \\
\text { esquizofrenia. }\end{array}$ \\
\hline 2012 & $\begin{array}{c}\text { Esquizofrenia; } \\
\text { qualidade de vida; } \\
\text { formaçáo de concei- } \\
\text { to; enfermagem psi- } \\
\text { quiátrica; pesquisa } \\
\text { qualitativa. }\end{array}$ & $\begin{array}{l}\text { Graduadas e } \\
\text { mestranda }\end{array}$ & Qualitativa exploratória & $\begin{array}{l}\text { Hospital das } \\
\text { Clínicas de } \\
\text { Marília (SP) }\end{array}$ & $\begin{array}{c}\text { Pessoa com } \\
\text { esquizofrenia }\end{array}$ \\
\hline 2013 & $\begin{array}{l}\text { Família; enferma- } \\
\text { gem psiquiátrica; } \\
\text { esquizofrenia. }\end{array}$ & $\begin{array}{l}\text { Doutoranda; } \\
\text { a outra autora } \\
\text { não informou } \\
\text { sua titulação. }\end{array}$ & Interacionismo simbólico & $\begin{array}{l}\text { Núcleo de Saúde } \\
\text { Mental do } \\
\text { Centro de Saúde } \\
\text { Escola e do } \\
\text { Ambulatório de } \\
\text { Esquizofrenia } \\
\text { - Hospital } \\
\text { das Clínicas de } \\
\text { Ribeirão Preto } \\
\text { (SP) }\end{array}$ & Familiares \\
\hline
\end{tabular}

Fonte: Elaborado pelos autores, 2015.

Foram encontrados apenas sete estudos, denotando-se uma singela produção científica, apesar da busca incessante dos últimos 32 anos de publicaçôes da REBEn. O primeiro artigo publicado com a temática esquizofrenia foi publicado em 2001, dessa forma, observa-se que se passaram 18 anos sem publicação sobre esse tema.

Tal dado pode ser evidenciado pela falta de interesse em publicar assuntos que tratam do adoecimento mental, em especial da esquizofrenia. Nos anos 1980 e 1990, já existia um preconceito de forma disseminada às pessoas com adoecimento mental, o que justifica a escassez de produçóes científicas e surgimento de produçôes na área da enfermagem a partir do século XXI15.

Nesse tocante, outros autores também acreditam que os indivíduos com transtorno mental são de difícil acesso, e mesmo em uso de fármacos, mostram-se com comportamentos imprevisíveis, o que afasta os pesquisadores, que acabam por escolher outro tema. Relatam ainda que vem aumentando significativamente o número de indivíduos que estigmatiza pessoas com distúrbios mentais ${ }^{15,16}$.

Não obstante, trata-se de um distúrbio neurológico que possui um vasto campo de pesquisas: na área do adoecimento psíquico, comportamental, orientaçóes prestadas aos familiares, sofrimento/sobrecarga familiar, uso de antipsicóticos, entre outros temas que podem ser abordados. Dessa maneira, não se compreende o porquê de não despertar interesse nos pesquisadores da área de enfermagem.

Além disso, as publicaçôes acadêmicas são um meio de transmitir para a comunidade científica o conhecimento e desenvolvimento de novas descobertas, novos materiais, técnicas e métodos de análise. A frequência de publicaçóes ajuda a sociedade científica a medir e avaliar uma área de conhecimento como emergente, consolidada ou decadente, através da análise quantitativa e qualitativa das pesquisas ${ }^{17}$.

Ao analisarmos a quantidade de autores, observou-se que a maioria dos artigos possuem $\geq 3$ autores e apenas um artigo foi desenvolvido por autor único. Durante a leitura aos artigos, pode ser visto que há uma parceria entre os alunos e professores dos cursos de graduação e pós-graduação, tendo como objetivo a disseminação do conhecimento através das publicações. 
Estudos revelam que artigos com autoria múltipla apresentam valores médios na produção três vezes maior que os artigos de autoria única e que a relação aluno-professor pode gerar produçóes científicas. Cabe ressaltar que as universidades junto aos seus docentes trabalham, na sua maioria, estimulando a formaçáo de pesquisadores por meio de grupos de estudo. Tal dado justifica as construção e desenvolvimento de pesquisas com três e mais autores ${ }^{18,19,20}$.

Em relação à classificação dos artigos por ano de publicação, os anos de 2005 (28,58\%) e 2012 (28,58\%) mostraram-se com mais produçôes - duas em cada ano. Quanto às demais produçóes, um (14,28\%) foi publicado em 2001, um (14,28\%) em 2011 e mais um (14,28\%) em 2013. Diferindo da atual pesquisa, um estudo que também trabalhou com levantamento bibliográfico sobre a esquizofrenia destacou que no ano de 2006 foi encontrado o maior número de publicaçóes (quatro) ${ }^{21}$.

Quanto à distribuição dos artigos por descritores, apenas uma publicação não utilizou a palavra "esquizofrenia". Dois estudos tinham como descritores "qualidade de vida", mais dois usaram "família", e três estudos utilizaram o termo "enfermagem psiquiátrica". Mesmo buscando com descritores como "sofrimento psíquico", que aborda doenças relacionadas à saúde mental de maneira geral, há uma redução no número de publicaçóes. Diversos autores trabalharam em consonância com o presente estudo, utilizando na maior parte os descritores: família, enfermagem e esquizofrenia ${ }^{19,21,22}$.

Sobre o estado federativo, pode ser observado que dos sete artigos analisados, a maioria dos autores $(71,4 \%)$ é proveniente da região Sudeste do país, oriundos do estado de São Paulo. Quanto às outras regiōes, foi encontrado apenas um $(14,28 \%)$ artigo proveniente da região Sul e mais um na região Nordeste (Tabela 1).

Ao analisar as pesquisas nos diversos bancos de dados nacionais, denotam-se as importantes contribuiçôes científicas que são desenvolvidas no Sudeste do país, devido à grande concentração de instituiçóes de excelência (Universidade de São Paulo - USP, Universidade Estadual de Campinas Unicamp e Universidade Federal de Sáo Paulo - Unifesp), todas no estado de São Paulo, correspondendo por mais de $50 \%$ das produções científicas no Brasil ${ }^{19,23}$.

Tabela 1: Distribuição de artigos publicados sobre esquizofrenia, segundo estado federativo. Maceió, 2015.

\begin{tabular}{|cc|}
\hline Estado federativo & Número de artigos publicados \\
\hline Ceará (CE) & 1 \\
\hline São Paulo (SP) & 5 \\
\hline Paraná (PR) & 1 \\
\hline Fonte: Elaborado pelos autores, 2015. & \\
\hline
\end{tabular}

Ao avaliar as titulaçôes dos autores, ressalta-se que a maioria das produçóes foi desenvolvida por mestres e doutores do curso de enfermagem. Em três estudos verificou-se a contribuição do Programa de Pósgraduação da USP na área de enfermagem psiquiátrica. Além disso, os mestrados foram nas áreas de: enfermagem psiquiátrica, saúde pública e mestrado em enfermagem. Náo houve participação de outros profissionais da área de saúde que estivessem envolvidos com pesquisas na área psiquiátrica, apenas uma autora possuía graduação em serviço social. Todos os outros autores foram identificados como enfermeiros. Dois artigos publicados no ano de 2012 não informaram as titulações de alguns autores.

Em contrapartida, autores relatam que há uma singela parcela de enfermeiros que participam dos programas de pós-graduação stricto sensu (mestrado e/ou doutorado), principalmente quando se trata da área psiquiátrica ${ }^{24,25}$. No entanto, a grande parcela dos enfermeiros que estão inseridos nos cursos de pós-graduação fornece excelentes contribuições no meio científico.

Sobre os cuidados indicados, os autores sugerem em seus estudos que a assistência em enfermagem psiquiátrica necessita conhecer as experiências vividas pelo ser esquizofrênico. Outros pesquisadores afirmaram que a família é a extensão do paciente, por isso, devem reconhecer sinais e sintomas de um possível surto esquizofrênico, assim como dos efeitos colaterais causados pelas medicaçóes. Ainda no tocante à família, denota-se na fala dos familiares que o cuidar é uma obrigação e que cumpri-la da melhor forma possível é um indicativo de que gostam do doente.

Sobretudo, autores posicionam-se quanto às mudanças de atitude dos profissionais da saúde, em especial, os enfermeiros. Tratam que o profissional enfermeiro precisa livrar-se de tantas atividades burocráticas e deve executar mais açôes humanísticas. Quando descreveram sobre a psicose, sugeriram a relaçáo com o Outro e que parte dos profissionais posicionem-se a partir da ética para o sucesso do tratamento. Corroborando os dados encontrados, autores relatam que a esquizofrenia deve incluir medidas psicossociais, reabilitativas, farmacoterápicas e deixam claro a importante presença durante $o$ tratamento dos profissionais de saúde e a participação ativa dos familiares $5,6,7,21$.

Percebe-se a necessidade de publicaçóes que abordem a pessoa com esquizofrenia e o papel da atenção primária, visto que poucos estudos encontrados em outros periódicos trazem de forma subjetiva a responsabilidade do profissional enfermeiro, tratando que esse profissional deve tomar decisóes e desenvolver um processo de mobilização de materiais e recursos para atender a família e o doente. É preciso desenvolver profissionais enfermeiros e todas as outras profissōes que fazem parte da Estratégia Saúde da Família (ESF), habilidades para saber/fazer: acolhimento; escutar; incluir paciente e família nas atividades coletivas e responsabilizar-se pelas 
pessoas que estáo sendo cuidadas, no compromisso de ajudar a família e a pessoa em sofrimento psíquico ${ }^{26}$.

Quando se trata da metodologia abordada, as sete publicaçóes foram de pesquisas de campo, sendo utilizada a abordagem qualitativa, e apenas um estudo trabalhou com o método quantiqualitativo. Em contrapeso, outro estudo evidenciou que apenas 1,9\% dos artigos pesquisados utilizaram a metodologia qualitativa $^{27,28}$.

O método qualitativo analisa a fundo os sujeitos investigados, dando-lhes a oportunidade de falar a respeito do tema abordado, desenvolvendo a escuta humanizada. Dessa forma, consegue obter informaçóes bastante particulares, além de ser uma abordagem que trabalha com aspiraçóes, valores, crenças, opiniōes e atitudes, de forma compreensiva e interpretativa ${ }^{28}$.

Em relação ao cenário da pesquisa, três artigos focaram instituiçóes hospitalares, o que pode evidenciar que a assistência e a produção de conhecimento da pessoa com esquizofrenia ainda se utilizam da instituição hospitalar como principal referência, contrariando a reforma psiquiátrica.
Tal dado pode ser explicado pela concentração de pessoas com esquizofrenia nas instituiçóes hospitalares. Apesar da reforma psiquiátrica e a construção de centro de atençáo psicossocial (CAPS), que foram criados com o intuito de reduzir o número de internaçóes e reinserir pacientes com adoecimento mental no meio familiar, ainda visualiza-se bastantes pacientes em unidade hospitalar ${ }^{29}$.

Dos sete artigos analisados, apenas um realizou entrevista no domicilio, e dois, nos CAPS. Esse é o local que parece ser o mais adequado, pelo fato de a pessoa com esquizofrenia estar em um ambiente mais familiarizado e sentir-se mais confortável e confiante para participar da pesquisa ${ }^{30}$.

Ao verificar os sujeitos investigados, percebemos que dos sete artigos analisados na REBEn, três $(42,86 \%)$ publicações direcionaram os estudos aos familiares cuidadores de pessoas com esquizofrenia; outros três $(42,86 \%)$ entrevistaram o próprio esquizofrênico; e apenas uma $(14,28 \%)$ pesquisa desenvolveu a técnica de formação de grupos de estudo em uma instituição hospitalar, e tiveram a preocupaçáo em colher informaçóes da família e da pessoa com esquizofrenia (Gráfico 1).

Gráfico 1: Distribuição dos artigos da REBEn sobre esquizofrenia, segundo sujeito investigado no período de 1983 a 2015.

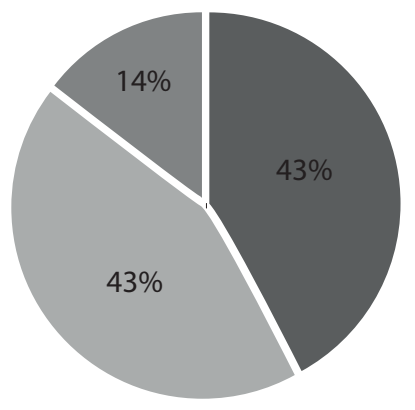

Fonte: Elaborado pelos autores, 2015.

Torna-se evidente que as pesquisas na área de enfermagem focam o paciente e a família, sendo um bom achado, pois são os protagonistas para o bom desenvolvimento do tratamento. Destarte, com a criaçáo do movimento da reforma psiquiátrica, a família passou a ter destaque no tratamento e cuidados necessários aos pacientes com adoecimento mental. Sobretudo, essas famílias encontram-se esquecidas e sem orientaçóes quanto aos males que podem ser ocasionados por essa doença ${ }^{6}$. Em consonância, outros estudos também centralizaram a família, evidenciando sua importância perante o tratamento ${ }^{21}$.

Outros autores relatam que os familiares almejam um serviço de saúde que preste uma assistência de qualidade, que acolham, para assim obterem esclarecimentos
Pessoa com Esquizofrenia

Familiares / Cuidadores

Pessoa com Esquizofrenia e familiares sobre a doença e aprenderem a lidar com situaçôes que antes não foram vividas. Tratam também que a experiência dos grupos focais permitem novos aprendizados e formas de lidar com a doença, além de os familiares compartilharem das mesmas dificuldades ${ }^{31}$.

Todavia, faltam estudos que tenham como sujeito investigado os profissionais de saúde, em especial da enfermagem, que abordem questionamentos quanto à assistência de enfermagem e orientaçóes prestadas a esses pacientes e suas famílias ${ }^{16,32}$.

Com relação à temática utilizada pelas produçóes científicas, não houve semelhança entre os estudos. Apesar de três trabalharem com o paciente esquizofrênico, os temas focalizavam várias vertentes, como: psicose do sujeito com esquizofrenia, diagnóstico, uso 
de clozapina e a realidade do viver com esquizofrenia. Dentre os que centralizaram a família, os autores preocuparam-se em avaliar o ajustamento familiar, a qualidade de vida da família e sentimentos dos familiares sobre o futuro. O tema esquizofrenia e família continuam sendo o alvo dos pesquisadores, principalmente no tocante à sobrecarga familiar, o pensamento do cuidador em relação ao futuro e quais as dificuldades são enfrentadas diante da patologia esquizofrenia ${ }^{1,5,21}$.

\section{Conclusão}

Com a presente revisão e leitura crítica dos textos científicos, conclui-se que há poucos estudos publicados na área de enfermagem sobre a esquizofrenia, fato evidenciado pela diminutiva produção que aborda a questão ao longo de 32 anos de publicação da REBEn. As produçóes científicas encontradas mostraram-se importantes para conhecer melhor as pessoas acometidas, o sofrimento e a vivência dos familiares/cuidadores de indivíduos com esquizofrenia. No entanto, há uma singela descrição sobre o papel dos profissionais de enfermagem, não havendo assim contribuiçóes para as mudanças nas práticas.

Apesar de a enfermagem brasileira apresentar o maior quantitativo de recursos humanos, percebe-se que há uma necessidade de ampliar as produçóes científicas, principalmente quando se trata do tema esquizofrenia e adoecimento mental. É necessário desmistificar condutas de profissionais e da própria sociedade.

É possível visualizar que nenhuma pesquisa trabalhou com profissionais da saúde e as repercussões da esquizofrenia para o estabelecimento de políticas públicas. Tais implicaçóes denotam que não houve preocupação em abordar as portarias que instituem melhorias para a vida das pessoas com esquizofrenia e consequentemente para seus familiares. O SUS também não foi citado durante os estudos, o que explicita a falta de pesquisas nessa área. Apesar das discussóes sobre a reforma psiquiátrica e dificuldades para implantar esse processo, estudos a respeito náo foram vistos.

Sabe-se pouco sobre a eficiência das intervençóes de enfermagem e quais principais orientaçóes são repassadas para os cuidadores de pessoas com esquizofrenia. Também não foram vislumbrados durante a pesquisa trabalhos que descrevessem problemas vividos pelo paciente e sua família e qual a atuação da equipe de saúde, em especial a conduta do enfermeiro, frente a essas dificuldades.
No decorrer do estudo, ficou evidente que a família é imprescindível no processo de reabilitação e socialização dos pacientes. Nessa perspectiva, a esquizofrenia requer uma maior participação dos profissionais de enfermagem, através de condutas humanizadas, como: acolhimento, escuta, orientaçóes sobre a doença e ajuda nos momentos de crise.

Sugere-se que novos trabalhos científicos deverão ser desenvolvidos para visualizar os anseios e perspectivas dos familiares e pacientes em relação ao futuro, suas dúvidas quanto à doença e a importância da contribuição da equipe multidisciplinar.

\section{Referências}

1. Gomes MS, Mello R. Sobrecarga gerada pelo convívio com o portador de esquizofrenia: enfermagem construindo o cuidado à família. Rev Eletrônica Saúde Mental Álcool Drog [Internet]. 2012 [citado em 2015 abr 17];8(1):2-8.Disponível em: http://pepsic.bvsalud.org/scielo.php?script=sci_arttext\&pid=\$180669762012000100002\&lng=pt\&tlng=pt.

2. OliveiraRM,FuregatoARF.Umcasaldeidososesualongaconvivência com quatro filhos esquizofrênicos. Rev Esc Enferm USP [Internet]. 2012 [citado em 2015 mar 10];46(3):61825. Disponível em: http://www.scielo.br/scielo. php?pid=S008062342012000300013\&script=sci_arttext.

3. Oliveira RM, Facina PCBR, Siqueira JAC. A realidade do viver com esquizofrenia. Rev Bras Enferm [Internet]. 2012 [citado em 2014 abr 14];65(2):30916. Disponível em: http://www.scielo.br/scielo. php?pid=S003471672012000200017\&script=sci_arttext.

4. Teixeira MB. Qualidade de vida de familiares cuidadores do doente esquizofrênico. Rev Bras Enferm [Internet]. 2005 [citado em 2014 abr 14];58(2):1715. Disponível em: http://www.scielo.br/scielo. php?script=sci_arttext\&pid=S003471672005000200008.

5. Giacon BCC, Galera SAF. Ajustamento familiar após o surgimento da esquizofrenia. Rev Bras Enferm [Internet]. 2013 [citado em 2014 out 10];66(3):3216. Disponível em: http://www.scielo.br/scielo. php?pid=S003471672013000300003\&script=sci_arttext.

6. Souza Filho MD, Sousa AO, Parente ACBV, Carvalho MMC. Avaliação da sobrecarga em familiares cuidadores de pacientes esquizofrênicos adultos. Psicol Estud [Internet]. 2010 [citado em 2014 abr 18]15(3):63947. Disponível em: http://www.scielo.br/scielo. php?pid=S141373722010000300022\&script=sci_arttext.

7. Silva RCB. Esquizofrenia: uma revisão. Psicol USP [Internet]. 2006 [citado em 2015 out 12];17(4):26385. Disponível em: http://www.scielo.br/scielo. php?script=sci_arttext $\&$ pid $=$ S0 10365642006000400014 . 
8. Araújo VJ, Coutinho NPS, Viveiros MTM, Leite EP, Corrêa RGCF. Schizophrenia: Daily Life and Experiences of Patients' Relatives. Rev Pesq Saúde [Internet]. 2015 [citado em 2016 feb 22];16(1):16-9. Disponível em: http://www.periodicoseletronicos.ufma.br/index.php/revistahuufma/article/view/4070/2152.

9. Vedana KGG, Miasso AI. A interação entre pessoas com esquizofrenia e familiares interfere na adesão medicamentosa? Acta Paul Enferm [Internet]. 2012 [citado em $2014 \mathrm{fev}$ 22];25(6):830-6.Disponívelem:http://www.scielo.br/scielo. php?script=sci_arttext\&pid=S010321002012000600002.

10. Souza RC, Pereira MAO, Scatena MCM. Família e transformação da atenção psiquiátrica: olhares que se (des)encontram. Rev Gaúcha Enferm [Internet]. 2002 [citado em 2014 abr 18];23(2):68-80. Disponível em: http://seer.ufrgs. br/RevistaGauchadeEnfermagem/article/view/4449.

11. Sales CA, Schülhi PAP, Santos EM, Tironi NM, D'artibale EF, Salci MA. Sentimentos de familiares sobre o futuro de um ser esquizofrênico: perspectivas para o cuidado de enfermagem. Rev Bras Enferm [Internet]. 2011 [citado em $2014 \mathrm{abr}$ 10];64(3):551-7.Disponívelem:http://www.scielo.br/scielo. php?script=sci_arttext $\&$ pid=S003471672011000300020.

12. Marconi MA, Lakatos EM. Fundamentos de metodologia científica. 5a ed. São Paulo: Atlas; 2003.

13. Mendes KDS, Silveira RCCP, Galvão CM. Revisão integrativa: método de pesquisa para a incorporação de evidências na saúde e na enfermagem. Texto \& Contexto Enferm [Internet]. 2008 [citado em $2014 \mathrm{dez}$ 18];17(4):758-64. Disponível em: www.scielo.br/pdf/tce/v17n4/18.pdf.

14. Cabral IE, Almeida Filho AJ. 85 anos de ABEn ${ }^{\circledR}$ e 80 de $R E B E n^{\oplus}$ promovendo o desenvolvimento científico e profissional da enfermagem brasileira. Rev Bras Enferm [Internet]. 2013 [citado em 2014 ago 22];66(spe):13-23. Disponível em: http://www.scielo.br/scielo.php?script=sci_arttext\&pi$\mathrm{d}=$ S003471672013000700002\&lng=pt\&nrm=iso.

15. Guarniero FB, Bellinghini RH, Gattaz WF. O estigma da esquizofrenia na mídia: um levantamento de notícias publicadas em veículos brasileiros de grande circulaçáo. Rev Psiquiatr Clín [Internet]. 2012 [citado em 2015 jan 18];39(3):80-4. Disponível em: http://www.scielo.br/pdf/ $\mathrm{rpc} / \mathrm{v} 39 \mathrm{n} 3 / \mathrm{a} 02 \mathrm{v} 39 \mathrm{n} 3$.

16. Loch AA, Hengartner MP, Guarniero FB, Lawson FL, Wang YP, Gattaz WF, et al. O estigma atribuído pelos psiquiatras aos indivíduos com esquizofrenia. Rev Psiquiatr Clín [Internet]. 2011 [citado em $2014 \mathrm{dez}$ 10];38(5):173-7. Disponível em: http://www.scielo.br/pdf/rpc/v38n5/a01v38n5.pdf.

17. Junior MAGF, Silva MS, Bezerra MP, Neto EAO, Silva GM. As dificuldades na elaboração de artigos científicos para alunos de graduação na área da ciência da informação: o caso do mini-curso de elaboraçáo de artigos científicos do curso de Gestão da Informação da UFPE. Encontro Regional de Estudantes de Biblioteconomia, Documentação, Ciência e Gestão da Informação; EREBD N/NE Gestão CARIRI 2011-2012. Disponível em: http://portaldeperiodicos.eci. ufmg.br/index.php/moci/article/view/2145/1338.
18. Araújo KM, Brandao MAG, Leta Jacqueline. Um perfil da produção científica de enfermagem em Hematologia, Hemoterapia e Transplante de medula óssea. Acta Paul Enferm [Internet]. 2007 [citado em 2014 out 16];20(1):82-6. Disponível em: http://dx.doi.org/10.1590/ S0103-21002007000100014.

19. Martini JG. Produção científica da enfermagem. Rev Bras Enferm [Internet]. 2009 [citado em $2015 \mathrm{dez}$ 18];62(6):807. Disponível em: http://dx.doi.org/10.1590/ S003471672009000600001.

20. Filho JLV. Periódicos científicos nas áreas de informação no Brasil: produção de artigos em colaboração e o gênero dos autores. Benancib [Internet]. 2013 [citado em 2016 jan 14]. Disponível em: http://repositorios.questoesemrede.uff.br/repositorios/bitstream/handle/123456789/615/ GT\%207\%20Txt\%2010\%20FILHO\%2c\%20Jayme\%20 Leiro\%20Vilan.\%20Peri\%C3\%B3dicos\%20cient \%C3\%ADficos...pdf?sequence $=1$.

21. Cordeiro FR, Terra MG, Piexak DR, Ely GZ, Freitas FF, Silva AA. Cuidados de enfermagem á pessoa com Esquizofrenia: revisão integrativa. Rev Enferm UFSM [Internet]. 2012 [citado em 2016 jan 15];2(1):174-81. Disponível em: file://C:/Users/Tamyssa/Downloads/3123-22984-1-PB.pdf.

22. Hansen J, Sato M, Kharecha P, Schuckmann K. Earth's Energy Imbalance and Implications. Atmos Chem Phys [Internet]. 2011 [citado em 2016 jan 10];11:1342149. Disponível em: http://www.atmos-chem-phys. net/11/13421/2011/acp-11-13421-2011.pdf.

23. Aquino LA, Aquino RFBA, Silva TC, Santos DF, Berger PG. Aplicação do fósforo e da irrigação na absorção e exportação de nutrientes pelo algodoeiro. Agriambi [Internet]. 2012 [citado em 2016 jan 30];16(4):35561. Disponível em: http://www.scielo.br/scielo. php?script=sci_arttext\&pid=S1415-43662012000400004.

24. Püschel VAA, Inácio MP, Pucci PPA. Inserção dos egressos da Escola de Enfermagem da USP no mercado de trabalho: facilidades e dificuldades. Rev Esc Enferm USP [Internet]. 2009 [citado em 2016 jan 28];43(3):535-42. Disponível em: http://www.scielo.br/pdf/reeusp/v43n3/a06v43n3.pdf.

25. Corrêa ACP, Araújo EF, Ribeiro AC, Pedrosa ICF. Perfil sociodemográfico e profissional dos enfermeiros da atençáo básica à saúde de Cuiabá - Mato Grosso. Rev Eletr Enf [Internet]. 2012 [citado em 2016 jan 28];14(1):171-80. Disponível em: http:// www.fen.ufg.br/revista/v14/n1/pdf/v14n1a20.pdf.

26. Coelho B, Silva A, Souza SL, Silva K, Silva PE, Pinto I, et al. Saúde mental no trabalho do enfermeiro da Atenção Primária de um município no Brasil. Rev Cuba Enferm [Internet]. 2015 [citado em 2016 fev 23];31(1). Disponível em: http:// www.revenfermeria.sld.cu/index.php/enf/article/view/626.

27. Oliveira RM, Furegato ARF. Esquizofrenia e dependência de tabaco: uma revisão integrativa. Rev Eletrôn Trim Enferm [Internet]. 2012 [citado em 2016 jan 25];25:40421. Disponível em: http://scielo.isciii.es/pdf/eg/v11n25/ pt_revision5.pdf. 
28. Minayo MCS, organizador. Pesquisa social: teoria, método e criatividade. 29a ed. Petrópolis: Vozes, 2010.

29. Pinheiro TLS, Cazola LHO, Sales CM, Andrade AR. Fatores relacionados com as reinternaçóes de portadores de esquizofrenia. Cogitare Enferm [Internet]. 2010 [citado em 2015 out 20];15(2):302-7. Disponível em: file://C:/Users/ Tamyssa/Downloads/17865-63298-3-PB.pdf.

30. Brasil. Portaria no 3.088, de 23 de dezembro de 2011. Institui a Rede de Atenção Psicossocial para pessoas com sofrimento ou transtorno mental e com necessidades decorrentes do uso de crack, álcool e outras drogas, no âmbito do Sistema Único de Saúde [Internet]. [citado em 2016 nov 9]. Disponível em: http://www.rio.rj.gov.br/dlstatic/10112/5202308/4139572/ PortariaN3.088RededeAtencaoPsicossocial.pdf.
31. Campana MC, Soares MH. Familiares de pessoas com esquizofrenia: sentimentos e atitudes frente ao comportamento agressivo. Cogitare Enferm [Internet]. 2015[citado em 2016 fev 22];20(2):338-44. Disponível em: https:// scholar.google.com.br/scholar?as_ylo=2015\&q=esquizofrenia+e+enfermagem \&hl=pt-BR\&as_sdt=0,5\&as_vis $=1$.

32. Hengartner MP, Loch AA, Lawson FL, Guarniero FB, Wang YP, Rössler W, et al. Atitudes de profissionais de saúde mental em relação a indivíduos com esquizofrenia: uma comparação transcultural entre Suíça e Brasil. Rev Psiquiatr Clín [Internet]. 2012 [citado em 2016 jan 12];39(4):11521. Disponível em: http://dx.doi.org/10.1590/ S0101-60832012000400001.

\section{Como citar este artigo:}

Silva JLR, Santos LMM, Lima UTS, Santos TS, Santos KS, Barros PMFP. Análise da produção científica sobre esquizofrenia. Rev. Aten. Saúde. 2016;14(50):70-78. 